\title{
Grow and \\ succeed with \\ fellow students
}

Hope Bretscher

When you look around the lecture hall of a hard physics class and see a lot of men, with just a sprinkling of women, it is easy to feel like you are in a competition with the other women. It can feel like only one female flavour will be viewed positively and as successful, while all the other women will be regarded as inferior. But each woman has a special spice! She can stand alone and deserves to study and succeed in physics, and can also add a flavour to the class that helps everyone to grow and succeed. Mixed into the pudding with all the other ingredients, each ingredient enhancing the others makes the strongest delicious pudding!

\section{Ingredients}

- A lot of men.

- A few women.

- Guts, bravery and boldness.

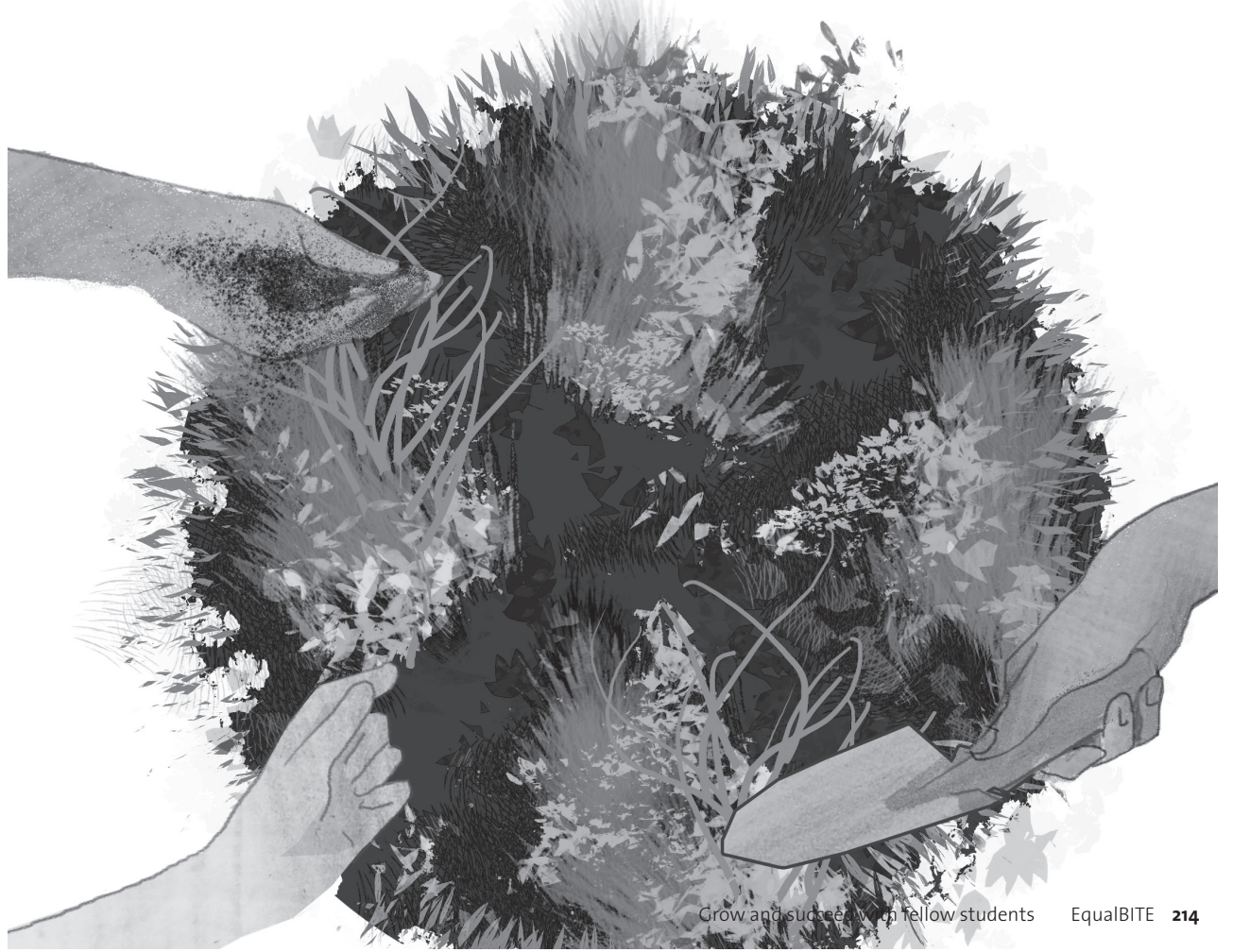

Hope Bretscher - 9789463511438 


\section{Method}

1. Remind yourself that you are sufficient as a person as you are, and do not need to be "the best" to make it.

2. Remind yourself that multiple women can succeed.

3. In class, go sit by another woman; introduce yourself and find out what they are interested in.

4. Study with the women - you'll do better if you work together and build on each other's strengths.

5. Study with the men. Note that they too may be struggling in some things and succeeding in others - you'll do better if you work together and build on each other's strengths.

6. Study in a group with both men and women. You will become less isolated and illustrate how each of you is valuable, debunking the stereotypes which can divide and weaken.

7. Go for a drink or a coffee with the men and women after a hard week. Remind each other that you are all people, interested in a subject, good at different things. Humanise each other.

8. Keep repeating steps 1-7 until all the flavours have mixed to create a tasty pudding, but one that you can still taste each distinctly and realise what an important ingredient it is.

\section{Cook's tips}

You may need to add a lot of guts and courage to get this right. Don't worry if at first there is a flavour of discomfort - it will transform with the other ingredients into something better! 